\title{
Omalizumab in Severe Refractory Vernal Keratoconjunctivitis in Children: Case Series and Review of the Literature
}

\author{
Serge Doan · Flore Amat - Eric Gabison - Sarah Saf • \\ Isabelle Cochereau $\cdot$ Jocelyne Just
}

Received: October 14, 2016 / Published online: December 1, 2016

(C) The Author(s) 2016. This article is published with open access at Springerlink.com

\begin{abstract}
Introduction: Vernal keratoconjunctivis (VKC) is a severe form of pediatric ocular allergy, characterized by acute and chronic corneoconjunctival inflammation that may lead to visual sequelae. Although topical immunosuppressive drugs such as cyclosporine are usually effective, some severe forms may be refractory and require prolonged steroid therapy. Very few papers report the use of
\end{abstract}

Enhanced content To view enhanced content for this article go to http://www.medengine.com/Redeem/ 3137F0606E0C4AA6.

S. Doan $(\bowtie) \cdot$ E. Gabison · I. Cochereau Ophthalmology Department of Fondation A de Rothschild and Hôpital Bichat, Paris, France e-mail: serge.doan@gmail.com

S. Doan · E. Gabison - I. Cochereau Université Paris Diderot, Sorbonne Paris Cité, Paris, France

F. Amat . S. Saf · J. Just

APHP-Hôpital Armand Trousseau, Centre de l'asthme et des allergies, Paris, France

F. Amat · S. Saf · J. Just

Université Pierre et Marie Curie, Paris, France

F. Amat . S. Saf $\cdot$ J. Just

Equipe EPAR, Institut Pierre Louis d'Epidémiologie et de Santé Publique, UMR_S1136, INSERM, Paris, France omalizumab in VKC in the literature. In the present study, we describe our clinical experience with omalizumab in severe VKC children.

Methods: We retrospectively reviewed the files of four boys treated with omalizumab because of severe VKC, defined as persistent corneal inflammation despite continuous topical 2\% cyclosporine and steroid eye drops. We also performed a literature review.

Results: Four boys, aged 7-13 years old, were treated. All children had asthma and one had severe lid eczema. Two patients had required intrapalpebral depot-steroid injections. Omalizumab was administered every 2 weeks by subcutaneous injections, at doses varying from 450 to $600 \mathrm{mg}$ per injection. Three patients out of four responded to the treatment, with a decrease in global symptoms (median symptom rating decreasing from 89 to 29 on a $100-\mathrm{mm}$ visual analog scale), frequency and in duration of the inflammatory flares, and also a decreased need for topical steroid. Their median clinical grade decreased from 4 to 3 (Bonini grading). However, the response was incomplete and they still had inflammatory corneoconjunctival flares despite continuous 
topical cyclosporine. On the other hand, asthma and lid eczema were completely controlled in these three patients. The fourth child did not respond to omalizumab and needed oral steroids for his VKC and his asthma. Noticeably, this latter patient did not have detectable sensitization to any allergen, contrary to the other cases. The treatment was stopped in this refractory case, but is still ongoing in all other cases, with a median duration of 33 months (range 16-42 months). In the literature (four cases), omalizumab may have a more complete efficacy in some cases, but the results are still variable.

Conclusion: Omalizumab is an interesting treatment in severe refractory forms of VKC, but its efficacy is incomplete in these very severe cases.

Keywords: Children; Cyclosporine; IgE; Immunomodulation; Severe allergy; Steroids; VKC

\section{INTRODUCTION}

Vernal keratoconjunctivitis (VKC) is a severe form of ocular allergy occurring mainly in children. It is characterized by chronic corneoconjunctival inflammation with giant conjunctival tarsal papillae and/or limbal inflammation. Inflammatory flares are more frequent during the hot season, usually from March to October in temperate climates, but may be perennial in sunny/tropical climates or late forms. Symptoms such as ocular itching, burning, photophobia and sticky eyes with mucous ropy discharge, have an important impact on the quality of life of the children. Furthermore, corneal involvement such as dense superficial punctate keratitis, shield ulcers and vernal plaques, are very symptomatic and may lead to neovascularized scars and visual sequelae.

Treatment of mild forms of VKC include wearing of sunglasses, ocular rinsing with balanced saline solution, and topical and systemic antihistamines $\mathrm{H} 1$ and topical mast cell stabilizers. In case of inflammatory flare with corneal involvement, topical steroids are needed. Dependence on steroids is very frequent, exposing children to unacceptable adverse effects such as ocular hypertension, glaucoma, cataract and infection. Besides, children are more susceptible to develop ocular hypertension than adults, and, also, monitoring of the ocular pressure may be difficult in non cooperative children. Topical immunosuppressive drugs are usually used in steroid-dependant cases. Cyclosporine A eye drops (0.5-2\%; CsA) are the most frequently used and studied, and have been shown to have a steroid sparing effect with an excellent safety profile. However, a significant proportion of patients are intolerant to CsA, and $16 \%$ and $5 \%$ do not respond to this treatment at month 1 and 3, respectively [1]. There are very few options in these refractory cases: supratarsal steroid injections are very potent, but may induce severe iatrogenic complications [2]; systemic steroids may be used only for a limited time; tacrolimus $0.03 \%$ skin ointment is not approved for conjunctival application, although it seems to have a very interesting effect [3]; tacrolimus $0.1 \%$ eye drops are probably also potent, but are available only in few asian countries for the moment [4]; mild cryotherapy of papillae is also an option for some [5], but we believe that there is a risk of conjunctival atrophy and scarring after repeated applications.

The pathophysiology of VKC combines IgE-mediated allergic reactions to 
non-IgE-mediated reactions [6]. IgE-mediated reactions characterize the classical immediate allergic reaction, also called anaphylaxis. As a prerequisite, sensitization to specific allergens such as pollen, dust mites, animal dander, mold, food allergens, leads to the production of specific immunoglobulins E (IgEs). When the allergen binds to specific IgEs present at the surface of a conjunctival mast cell, a degranulation of preformed mediators such as histamine, chymase and tryptase by the mast cell occurs. These mediators are responsible for the classical symptoms and signs of the early allergic phase: itching, redness and edema. A late phase occurs after $6 \mathrm{~h}$, as a result of the production of postformed inflammatory mediators such as leukotrienes and prostaglandins by the mast cell, leading to the infiltration of eosinophils, neutrophils and macrophages in the tissue. Eosinophils play a major role in inflammation and in tissular lesions such as epitheliopathy in VKC. CD4+ $\mathrm{TH} 2$ cells seem to drive these IgE-dependant reactions in VKC [7]. However, only 50\% of VKC patients have identified sensitization to specific allergens. Indeed, several types of non-IgE-mediated reactions also occur in VKC, among which direct activation of $\mathrm{T}$ cells, dendritic cells, enzymatic systems, metalloproteases, and non-specific hyper-reactivity are included [8].

Omalizumab is a monoclonal chimeric anti-IgE antibody that binds to the $\mathrm{C} \varepsilon 3$ domain of free circulating IgE, resulting in inactive immune complexes that are cleared from the plasma [9]. It can reduce circulating free IgE up to 99\%, thus suppressing the activation of mast cells [10] and down-regulating the expression of the $\operatorname{IgE}$ receptors FceRI at the surface of basophiles and mast cells. Hence, the IgE-mediated reactions are less likely to occur [11].
Several studies have shown the efficacy of omalizumab in allergic asthma since the initial publications in 1999 [12], leading to the approval of omalizumab for this indication in the USA in 2003 and in France in 2006. In patients with moderate to severe allergic asthma with dependence on inhaled steroids, the addition of omalizumab reduces asthma exacerbations and decreases inhaled corticosteroid and rescue medication use. Furthermore, a few studies have shown the efficacy of this molecule in seasonal allergic rhinitis $[13,14]$.

Omalizumab is administered systematically by subcutaneous injections every 2-4 weeks, according to the weight and the level of blood total IgEs. It has initially been authorized for the treatment of severe asthma. Few case reports suggest its efficacy in VKC and atopic keratoconjunctivitis $[15,16]$. The purpose of this study is to report our clinical experience with omalizumab in severe refractory cases of VKC in children, and to review the literature.

\section{METHODS}

\section{Design}

This was a non-controlled, open-label, retrospective case series.

We reviewed the files of four boys (eight eyes), suffering from severe VKC, and who were treated with omalizumab.

For each patient, we collected the ocular and extra-ocular data concerning their allergic diseases.

At each visit, a global symptom score was assessed by a visual analog scale (from 0 if no symptoms to $100 \mathrm{~mm}$ if maximum symptoms).

VKC severity was graded according to Bonini's classification [17]: grade 0: no 
symptoms, no superficial punctate keratitis (SPK); grade 1: mild symptoms, no SPK; grade 2: photophobia, no SPK; grade 3: photophobia, moderate SPK; grade 4: photophobia, severe SPK or corneal ulcer.

Response to treatment was graded as follows: total control: no inflammatory flare; partial control: decrease in the number and/or intensity of the inflammatory flares; failure: no change in the evolution.

The retrospective analysis was approved by the institutional ethical committee of Fondation A de Rothschild. The parents provided written informed consent for publication of clinical data.

\section{RESULTS}

Patients were aged 7-13 years. They all suffered from very severe VKC, with symptom scores ranging from 72 to $100 \mathrm{~mm}$, and a clinical grade of 4 in all cases, according to Bonini's classification. Their disease was resistant to topical steroids and topical cyclosporine 2\% eye drops, with persistent superficial punctate keratitis despite these treatments for more than 2 years (at least 8 months per year; Table 1 ). Patient \#2 developed a shield ulcer on the left eye, requiring corneal scraping 2 years earlier. In patients \#2 and 4, supratarsal depot triamcinolone injections had even been performed once a year for the 2 previous years, and were the only way to control corneal inflammation at this moment.

All patients suffered from asthma, and also from severe rhinitis in three cases (\#1, 2 and 3) and severe atopic dermatitis with periocular involvement in case \#3. All patients were polysensitized, except patient \#4 for whom no sensitization was found. Total serum IgE ranged from 141 to $8000 \mathrm{KUI} / \mathrm{L}$.
Omalizumab was primarily introduced because of the severe ocular involvement. It was administered every 2 weeks by subcutaneous injections, at doses varying from 450 to $600 \mathrm{mg}$ per injection.

In three children (cases \#1, 2 and 3), the ocular response to omalizumab was graded as a partial control: symptom scores dropped down to values ranging from 30 to $52 \mathrm{~mm}$ at 8 weeks months and from 21 to $31 \mathrm{~mm}$ at the end of follow-up. Clinical grading decreased from grade 4 to grade 3 in these 3 cases (Fig. 1). However, inflammatory flares with dense punctate superficial keratitis (3-5 episodes per year) still occurred but were much shorter and easily controlled with topical steroids, which were then only needed during the inflammatory flares for a short course, and not continuously as before omalizumab treatment. Corneal inflammation returned to zero between the inflammatory flares, which was never the case before treatment. Topical cyclosporine was continued in cases \#1 and 2, and stopped in case \#3 because of allergy to the eye drops, without consequence. No palpebral steroid injections were needed in any of those three cases.

In these three responder cases, asthma was totally controlled after 4 months, and eczema also healed completely after 9 months in case \#3. Rhinitis was only partially controlled, with still noticeable nasal obstruction and intermittent need for nasal steroids.

Omalizumab was stopped after 16 months in case \#1, and has been administered for 33 and 42 months, still ongoing in cases \#2 and 3, respectively.

Case \#4 did not respond at all to omalizumab, which was stopped after 6 months. Asthma and VKC still needed high doses of topical steroids, and also oral steroid 


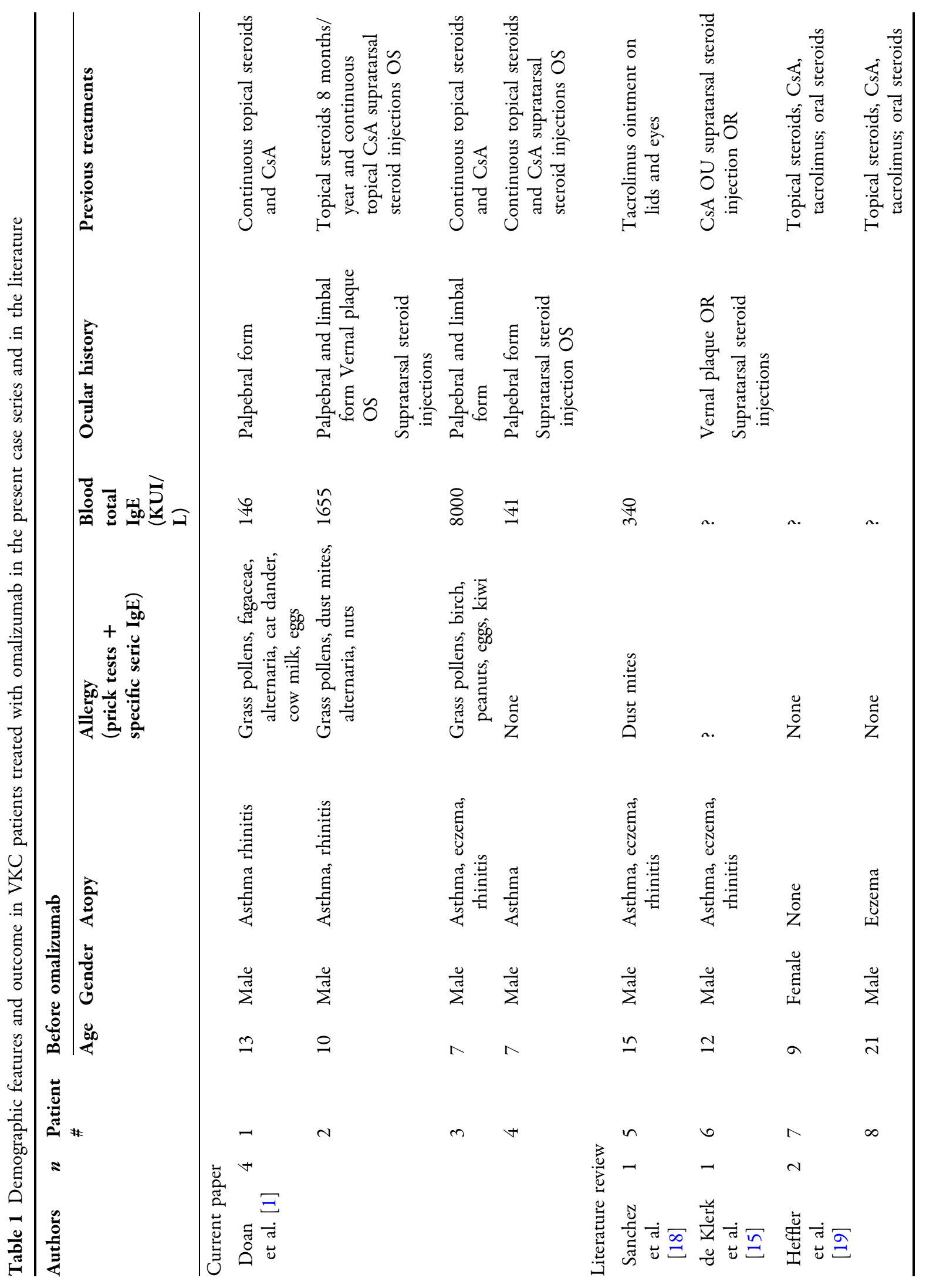




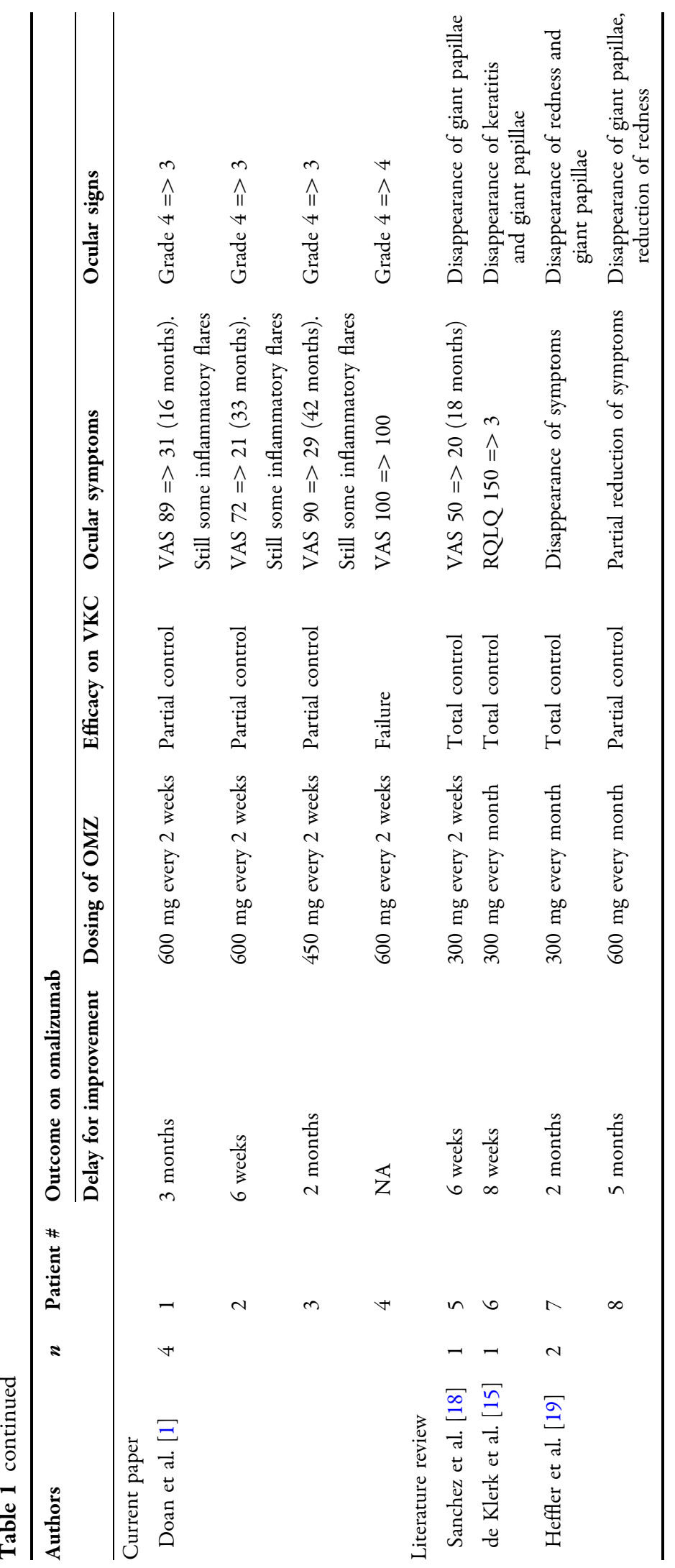




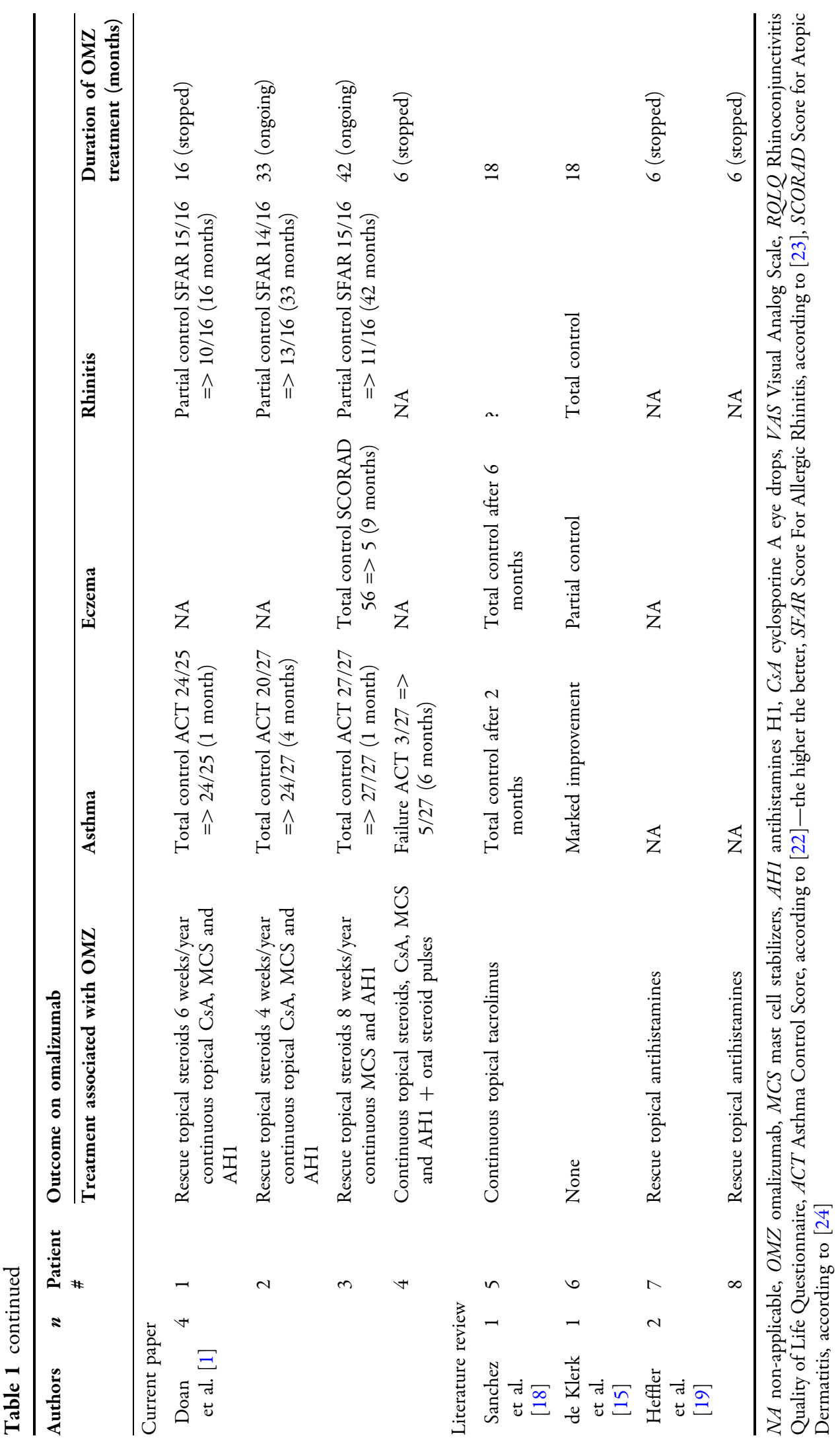



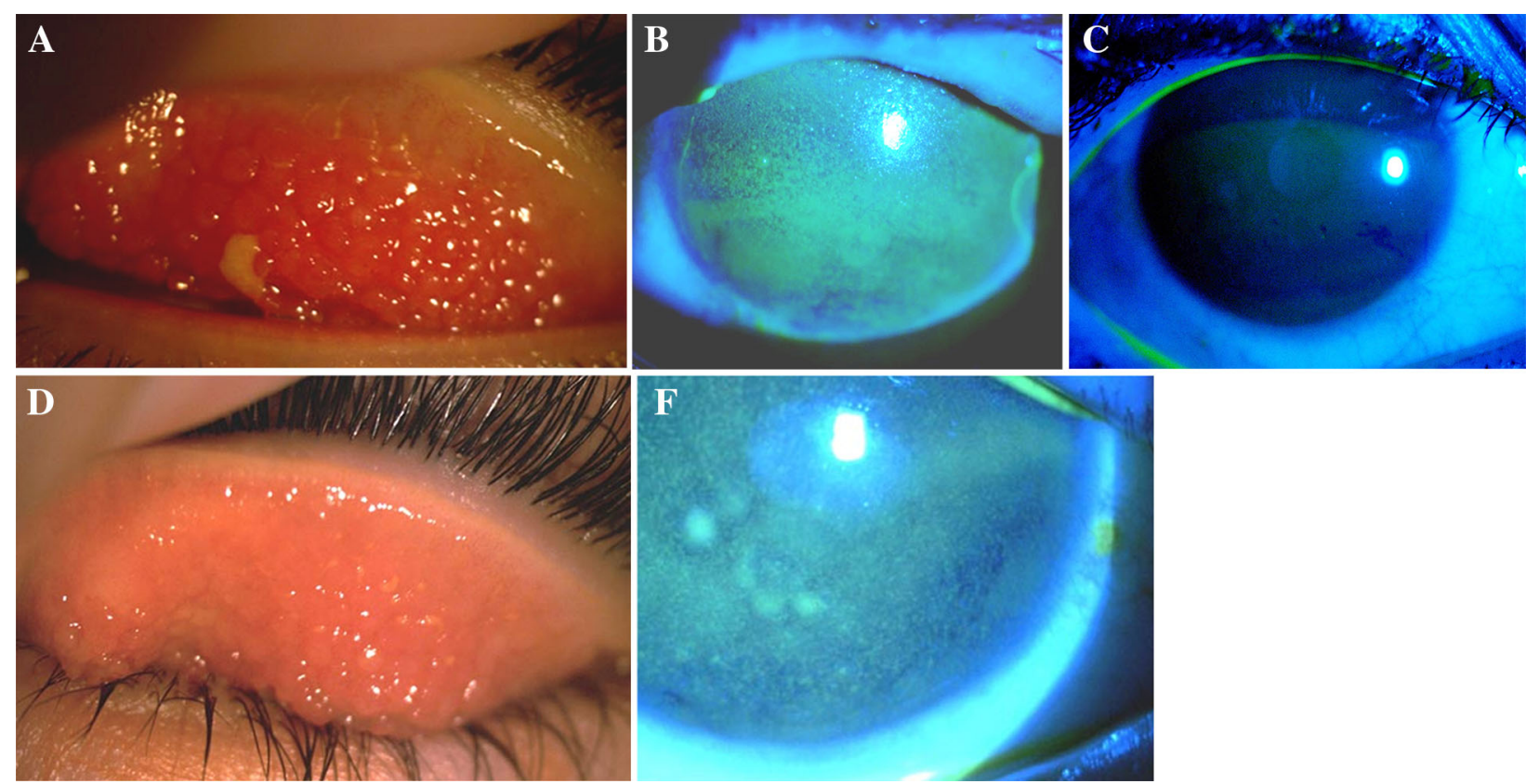

Fig. 1 Patient \#3, before treatment (a, b) and after 3 months of omalizumab (c). At month 4, a recurrence of corneal inflammation occurred (d, e). Superior palpebral conjunctival papillar hypertrophy $(\mathbf{a}, \mathbf{c})$ and corneal fluorescein staining $(\mathbf{b}, \mathbf{d}, \mathbf{e})$, showing partial diminution

pulses in order to control pulmonary and ocular inflammation. Noticeably, this patient was the only one to have no evident sensitization at allergy workout. His serum IgE level was 141 pre-treatment, and 77 post-treatment.

Omalizumab was well tolerated in our four patients, and no adverse effects were noted.

\section{LITERATURE REVIEW}

We performed a literature search in PubMed. The keywords were vernal keratoconjunctivitis, atopic keratoconjunctivitis, allergic conjunctivitis, and omalizumab. There were only case reports, with a total of four children with VKC who were treated with omalizumab. The cases are summarized in Table 1.

Sanchez et al. described the first VKC patient treated with omalizumab in 2012 [18]. This severe case had unsuccessfully been treated with of inflammation. In this patient, several episodes of corneoconjunctival inflammation occurred on omalizumab, but were less frequent and easier to control, compared to before omalizumab treatment

topical steroids/cyclosporine, then topical tacrolimus $0.03 \%$ ointment for more than 2 years. Although this latter treatment had been maintained, omalizumab clearly allowed for a major reduction of the symptoms after 3-6 months, with a disappearance of the conjunctival tarsal giant papillae after 10 months. No steroid treatment was needed while on omalizumab. Extra ocular involvement (asthma, atopic dermatitis and rhinitis) also improved with the treatment. The effects were still present after 18 months of treatment.

In 2013, de Klerk et al. [15] described the second case of VKC, who had developed a corneal shield ulcer despite topical steroids on the right eye, leading to a subtarsal injection of triamcinolone. Omalizumab was introduced because of non-controlled severe asthma and rhinitis. After 2 months of treatment, ocular 
symptoms had improved, as well as asthma and rhinitis. After 18 months, the ocular involvement was completely controlled, with a disappearance of the giant conjunctival papillae and of the keratitis. Asthma and rhinitis were completely controlled, although eczema was still moderately active. Although this child had had a severe corneal complication, it is difficult to grade the real severity of his case, for topical cyclosporine had been prescribed for a very short time before omalizumab was initiated for a non-ocular reason.

Recently, Heffler et al. reported two cases, aged 9 (girl) and 21 (man) [19, 20]. The particularities of their study are that none of the patients had asthma, and the efficacy was assessed by clinical parameters, but also by eosinophil count on conjunctival scrape smears. The cases were unresponsive to topical corticosteroids, cyclosporine and tacrolimus, and partially responsive to oral steroids. The younger patient completely responded to omalizumab within 2 months in terms of symptoms and eye redness. The older patient only responded partially and progressively within 5 months. He also suffered from eczema, and, given his age, might have, in fact, a frontier form between AKC and VKC. The eczema was not modified by omalizumab. Giant papillae disappeared after 6 months in both cases. The eosinophil count on conjunctival smears was also dramatically reduced after 6 months of treatment, from $69 \%$ in the child and $51 \%$ in the young man to $3 \%$ and $0 \%$, respectively. Omalizumab was stopped after 6 months in both cases, without recurrence after 4 months.

Williams et al. published an expert review in 2005, where they reported six patients with severe AKC [21]. Unfortunately, the description of their cases was incomplete. Although three patients were qualified as VKC in their summary table, it is likely that all patients were, in fact, AKC patients, as stated in the text, for their age ranged from 27 to 71 years. All patients were on topical and systemic steroids. It seems that symptoms and signs decreased globally, although some fluctuation was noted, following the evolution of the general allergy symptoms. The need for topical steroids was decreased in all patients but one. No patient received topical cyclosporine.

\section{DISCUSSION}

Omalizumab seems to be a potent treatment for refractory forms of VKC. It allows a reduction of symptoms and corneoconjunctival inflammation. Its efficacy is, however, variable among patients. One patient out of eight did not respond at all. Response was considered as partial in four patients, and complete in three. This variability could reflect the incomplete responsibility of IgE-mediated mechanisms in $\mathrm{VKC}$, as proposed in the new classification of allergic eye diseases published in a position paper of the European Academy of Allergy and Clinical Immunology written by Leonardi et al. [6]. Case \#4, for whom omalizumab failed, was the only child of our series without any allergic sensitization. Absence of allergy might be a risk factor of treatment failure, although the two patients reported by Heffler et al. were also non-allergic but responded well to the treatment. Besides, elevated total IgE blood levels did not seem to be a predictive factor of ocular response in these patients.

In patients with very high inflammatory levels, omalizumab may only have a partial effect. However, the patients are very happy with the treatment, because the inflammatory flares become more seldom and easily controlled with topical steroids (cases \#1, 2 and 3) or antihistamines (cases \#7 and 8). 
Patients \#1, 2 and 3 also suffered from rhinitis, which was only partially controlled by omalizumab, whereas asthma and eczema totally healed within 4 months. Omalizumab might have a lower effect on the eyes and nose, compared to the lungs and skin, although patient \#8 did not show any improvement of his eczema on omalizumab. The mechanisms of nasal and ocular inflammation may be more IgE-independent than asthma and eczema.

Several questions remain concerning the optimal therapeutic scheme in VKC patients. The dosing of omalizumab varied from $300 \mathrm{mg}$ every month to $600 \mathrm{mg}$ every 2 weeks, which represents a four-fold variation between different teams, but there are no data available in these patients for a dose-effect relation.

Among all the publications, our patients have the longest duration of treatment by omalizumab, up to 42 months. However, VKC is seasonal in $70 \%$ of patients, with an increase of inflammatory flares between February and October. It is not clear whether omalizumab could be stopped during winter, but it seems that this practice has been adopted by some teams.

The cost of omalizumab remains a concern (several thousand euros in Europe), but in most severe cases of VKC, we believe that such a cost is justified. Although the effect was partial in our patients, the occurrence of severe corneal complications was prevented, and the quality of life of the patients much better. In the future, other key mechanisms such as those involving eosinophils should be targeted by new treatments.

\section{CONCLUSION}

Omalizumab is an interesting treatment for refractory forms of VKC. Its efficacy can be partial in most severe forms, but reduction of signs, symptoms and anti-inflammatory treatment is almost always noted. The best patient profile and treatment regimen are yet to be determined. Controlled studies are needed in the future.

\section{ACKNOWLEDGEMENTS}

No funding or sponsorship was received for this study or publication of this article. All named authors meet the International Committee of Medical Journal Editors (ICMJE) criteria for authorship for this manuscript, take responsibility for the integrity of the work as a whole, and have given final approval for the version to be published.

Disclosures. F. Amat reports personal fees from Novartis. J. Just is a consultant for Novartis. S. Doan, E. Gabison, S. Saf and I. Cochereau have nothing to disclose.

Compliance with Ethics Guidelines. The retrospective analysis was approved by the institutional ethical committee of Fondation A de Rothschild. The parents provided written informed consent for publication of clinical data.

Open Access. This article is distributed under the terms of the Creative Commons Attribution-NonCommercial 4.0 International License (http://creativecommons.org/licenses/ by-nc/4.0/), which permits any noncommercial use, distribution, and reproduction in any medium, provided you give appropriate credit to the original author(s) and the source, provide a link to the Creative Commons license, and indicate if changes were made. 


\section{REFERENCES}

1. Doan S, Gabison E, Abitbol O, Gatinel D, Chast F, Hoang-Xuan T. Efficacy of topical 2\% cyclosporine $\mathrm{A}$ as a steroid-sparing agent in steroid-dependent vernal keratoconjunctivitis. J Fr Ophtalmol. 2007;30(7):697-701.

2. Zaouali S, Kahloun R, Attia S, Jelliti B, Trigui M, Yahia SB, et al. Supratarsal injection of triamcinolone acetonide and childhood allergic keratoconjunctivitis. Int Ophthalmol. 2012;32(2):99-106.

3. Attas-Fox L, Barkana Y, Iskhakov V, Rayvich S, Gerber Y, Morad Y, et al. Topical tacrolimus 0.03\% ointment for intractable allergic conjunctivitis: an open-label pilot study. Curr Eye Res. 2008;33(7):545-9.

4. Fukushima A, Ohashi Y, Ebihara N, Uchio E, Okamoto S, Kumagai N, et al. Therapeutic effects of $0.1 \%$ tacrolimus eye drops for refractory allergic ocular diseases with proliferative lesion or corneal involvement. Br J Ophthalmol. 2014;98(8):1023-7.

5. Sankarkumar T, Panda A, Angra SK. Efficacy of cryotherapy in vernal catarrh. Ann Ophthalmol. 1992;24(7):253-6.

6. Leonardi A, Bogacka E, Fauquert JL, Kowalski ML, Groblewska A, Jedrzejczak-Czechowicz $M$, et al. Ocular allergy: recognizing and diagnosing hypersensitivity disorders of the ocular surface. Allergy. 2012;67(11):1327-37.

7. Leonardi A, DeFranchis G, Zancanaro F, Crivellari G, De Paoli M, Plebani M, et al. Identification of local Th2 and Th0 lymphocytes in vernal conjunctivitis by cytokine flow cytometry. Invest Ophthalmol Vis Sci. 1999;40(12):3036-40.

8. Leonardi A, De Dominicis C, Motterle L. Immunopathogenesis of ocular allergy: a schematic approach to different clinical entities. Curr Opin Allergy Clin Immunol. 2007;7(5):429-35.

9. Buhl R. Anti-IgE antibodies for the treatment of asthma. Curr Opin Pulm Med. 2005;11(1):27-34.

10. MacGlashan DW Jr, Bochner BS, Adelman DC, Jardieu PM, Togias A, McKenzie-White J, et al. Down-regulation of $\mathrm{Fc}($ epsilon)RI expression on human basophils during in vivo treatment of atopic patients with anti-IgE antibody. J Immunol. 1997;158(3):1438-45.

11. Beck LA, Marcotte GV, MacGlashan D, Togias A, Saini S. Omalizumab-induced reductions in mast cell Fce psilon RI expression and function. J Allergy Clin Immunol. 2004;114(3):527-30.

12. Milgrom H, Fick RB Jr, Su JQ, Reimann JD, Bush RK, Watrous ML, et al. Treatment of allergic asthma with monoclonal anti-IgE antibody. rhuMAb-E25 Study Group. N Engl J Med. 1999;341(26):1966-73.

13. Casale TB, Condemi J, LaForce C, Nayak A, Rowe M, Watrous $M$, et al. Effect of omalizumab on symptoms of seasonal allergic rhinitis: a randomized controlled trial. JAMA. 2001;286(23):2956-67.

14. Okubo $\mathrm{K}$, Ogino $\mathrm{S}$, Nagakura $\mathrm{T}$, Ishikawa $\mathrm{T}$. Omalizumab is effective and safe in the treatment of Japanese cedar pollen-induced seasonal allergic rhinitis. Allergol Int. 2006;55(4):379-86.

15. de Klerk TA, Sharma V, Arkwright PD, Biswas S. Severe vernal keratoconjunctivitis successfully treated with subcutaneous omalizumab. J AAPOS. 2013;17(3):305-6.

16. Taille C, Doan S, Neukirch C, Aubier M. Omalizumab for severe atopic keratoconjunctivitis. BMJ Case Rep 2010;2010.

17. Bonini S, Sacchetti M, Mantelli F, Lambiase A. Clinical grading of vernal keratoconjunctivitis. Curr Opin Allergy Clin Immunol. 2007;7(5):436-41.

18. Sanchez J, Cardona R. Omalizumab. An option in vernal keratoconjunctivitis? Allergol Immunopathol (Madr) 2012;40:319-20.

19. Heffler E, Picardi G, Liuzzo MT, Pistorio MP, Crimi N. Omalizumab treatment of vernal keratoconjunctivitis. JAMA Ophthalmol. 2016;134(4):461-3.

20. Picardi G, Liuzzo MT, Sichili S, Nicolosi G, Pistorio $\mathrm{MP}$, Crimi $\mathrm{N}$, et al. Two cases of severe vernal kerato-conjunctivitis successfully treated with omalizumab and monitored by conjunctival cytology (poster). In: 60th congress of the European Academy of Allergy and Clinical Immunology (EAACI). Vienna, Austria; 2016.

21. Williams PB, Sheppard JD Jr. Omalizumab: a future innovation for treatment of severe ocular allergy? Expert Opin Biol Ther. 2005;5(12):1603-9.

22. Liu AH, Zeiger R, Sorkness C, Mahr T, Ostrom N, Burgess S, et al. Development and cross-sectional validation of the Childhood Asthma Control Test. J Allergy Clin Immunol. 2007;119(4):817-25.

23. Annesi-Maesano I, Didier A, Klossek M, Chanal I, Moreau D, Bousquet J. The score for allergic rhinitis 
(SFAR): a simple and valid assessment method in population studies. Allergy. 2002;57(2):107-14.

24. Oranje AP, Glazenburg EJ, Wolkerstorfer A, de Waard-van der Spek FB. Practical issues on interpretation of scoring atopic dermatitis: the SCORAD index, objective SCORAD and the three-item severity score. $\mathrm{Br} J$ Dermatol. 2007;157(4):645-8. 